\title{
Neutral aldoses as source indicators for marine snow
}

\author{
Annelie Skoog $^{\mathrm{a}, *}$, Alice Alldredge ${ }^{\mathrm{b}}$, Uta Passow ${ }^{\mathrm{c}, 1}$, John Dunne ${ }^{\mathrm{d}, 2}$, James Murray ${ }^{\mathrm{d}}$ \\ ${ }^{a}$ Department of Marine Science, University of Connecticut, Groton, Connecticut 06340-0648, USA \\ ${ }^{\mathrm{b}}$ Department of Ecology, Evolution and Marine Biology, University of California Santa Barbara, Santa Barbara, CA 93106, USA \\ ${ }^{\mathrm{c}}$ Marine Science Institute, University of California Santa Barbara, Santa Barbara, CA 93106, USA \\ ${ }^{\mathrm{d}}$ School of Oceanography, University of Washington, Seattle, Washington 98195-5531, USA
}

Received 5 April 2007; received in revised form 6 November 2007; accepted 20 November 2007

Available online 28 November 2007

\begin{abstract}
The chemical characteristics of aggregating material in the marine environment are largely unknown. We investigated neutral aldose (NA) abundance and composition in aggregation of marine snow and other organic matter (OM) size fractions in the field. Four sample sets were fractionated using membrane filtration and ultrafiltration into the following size fractions: particulate material, high-molecular-weight (HMW) material, and low-molecular-weight (LMW) material. We also collected three sample sets of marine-snow aggregates. Each sample set contained small, medium, and large aggregate size fractions and each size fraction consisted of 25-50 aggregates. For 7 marine-snow samples and for each water-sample size fraction, we determined monomeric and polymeric NA concentration, NA yield (amount of NA-C normalized to organic carbon), and composition; total organic carbon (TOC) concentration; transparent exopolymer particles (TEP) concentration, and TEP propensity (TEP concentration after inducing TEP formation in filtered samples). This is the first study to include compound-specific NA determinations on these four marine OM size fractions.

The mass balances of organic carbon and NA indicated that there were no serious contamination or loss problems. Concentrations, yields, and NA mol fractions in water samples were similar to results from other studies. Glucose and galactose had the highest relative abundance in all size fractions. The NA yield increased with increasing molecular weight or particle size for all fractions except marine snow. The NA yield increased in the order: $\mathrm{LMW}<$ marine snow $<\mathrm{HMW}<$ particles. Marine snow had a higher average NA yield than the LMW fraction, but lower than particle and HMW-fractions. This indicates that OM in marine snow could have been diagenetically derived from particulate and HMW-fractions, that is, marine snow may include material from the particulate and the colloidal phase.

TEP concentration or TEP propensity was positively correlated with concentrations of all individual NAs as well as the sum NA concentrations, indicating that TEP contains neutral sugars in addition to the acidic polysaccharides stained in the determination of TEP concentrations.

Despite the relatively low NA yield in marine snow, marine snow was enriched in NA when compared with seawater, with enrichment factors of 34-225 (average 125). By combining data from this study with data from other studies, we estimate that $<10 \%$ of carbohydrates in marine snow comprise NAs.

There was no clear correlation between marine-snow aggregate size and NA yield, that is, there appears to be no general age difference between small and large marine-snow aggregates. NA composition was similar among different marine-snow size fracions
\end{abstract}

\footnotetext{
* Corresponding author. Tel.: +1 860405 9220; fax: +1 8604059153.

E-mail address: annelie.Skoog@uconn.edu (A. Skoog).

${ }^{1}$ Current address: Alfred-Wegener-Institute for Marine and Polar Research, Am Handelshafen 12, D-27515 Bremerhaven, Germany.

${ }^{2}$ Current address: Atmospheric and Oceanic Sciences, Princeton University, CN710 Sayre Hall, Princeton, NJ 08544-0710, USA.
} 
collected during the same day, indicating that aggregation/disaggregation reactions resulted in homogenizing NA composition in marine-snow aggregates of all sizes. The NA composition of marine snow was different from that of other OM size fractions, indicating either that bacterial degradation has modified the composition of marine snow to a larger extent than other OM size fractions or that marine snow is formed through the aggregation of selected subcomponents of OM.

(C) 2007 Elsevier B.V. All rights reserved.

Keywords: Neutral aldoses; Marine snow; Aggregation; Colloids; Organic matter; Biological lability; USA, California, Santa Barbara Channel

\section{Introduction}

A number of processes in the marine environment result in the formation of larger organic matter (OM) from smaller OM. It is well known that small marine particulate organic matter (POM) can aggregate to larger POM (Jackson and Burd, 1998). In addition, POM has been shown to form from dissolved organic matter (DOM) through aggregation processes of colloidal organic matter (Kepkay, 1994), coagulation on bubble surfaces (Kepkay and Johnson, 1988), and through sorption of dissolved material to organic (Hwang et al., 2006) and inorganic particles (Edwards et al., 1996; Satterberg et al., 2003; Schlautman and Morgan, 1994). Recently, it has also been shown that colloidal marine OM can form gels (see for example Chin et al. (1998)) if divalent cations are present. Hence, there are several different processes in the ocean that transfer $\mathrm{OM}$ from the dissolved to the particulate phase.

Within the POM pool, transparent exopolymer particles (TEP) have been found in large numbers in the coastal (Alldredge et al., 1993) and open ocean (Engel, 2004). TEP affect aggregation in a number of ways: TEP may rapidly form larger aggregates (Alldredge et al., 1993), appear to affect particle stickiness (Jackson, 1995), and may be essential for initiating particle aggregation at low biomass concentrations (Engel, 2004). From the first studies of TEP (Alldredge et al., 1993), it has been suggested that TEP formation depends on divalent cation bridging, which ties TEP formation to the recently proposed marine gel formation (Chin et al., 1998), mentioned above. There is also an additional connection between TEP and gels-TEP may form from dissolved precursors (Passow, 2000), just like marine gels. TEP formation from dissolved precursors has been called TEP propensity (Passow, 2000).

A gel is defined as a stabilized suspension of a colloidal material and since colloidal material is part of the dissolved pool, gels form, by definition, from the dissolved phase. The chemistry of the colloidal material that would comprise marine gels has been relatively well studied after concentrating a subfraction of the colloidal material using ultrafiltration techniques. One of the main conclusions is that the colloidal, or high-molecular- weight (HMW), OM contains a higher fraction of biologically-labile OM than low-molecular-weight (LMW) OM (Amon et al., 2001). Further, it has been shown that neutral aldoses (NA) comprise the largest identified carbohydrate fraction in HMW OM (Skoog and Benner, 1997).

NA are useful as diagenetic indicators, that is, for tracing OM through aggregation and degradation processes. NA are biologically labile, and yield (defined as amount normalized to organic carbon) of biologically-labile compounds has been proposed as a robust indicator of diagenetic status and age for both POM (Cowie and Hedges, 1994) and DOM (Amon et al., 2001). High yield of biologically-labile compounds is an indicator of fresh OM, while low yield indicates older OM subjected to more diagenetic change. This connection between relative amount of biologically-labile compounds and age has recently been confirmed by combined isotope and biochemical-indicator approaches (Loh et al., 2004, 2006). Earlier studies also proposed a connection between particle size and biological lability (Amon and Benner, 1996), as indicated by the yield of biologically-labile compounds. That is, yield of biologically-labile compounds indicated that larger $\mathrm{OM}$ was younger than smaller $\mathrm{OM}$, when comparing LMW OM, colloidal OM, and POM. In addition to using NA yield as a diagenetic and source indicator in aggregation studies, NA composition may give valuable insight into the chemistry of aggregated material and its' precursors, which is presently essentially unknown.

We aimed to investigate NA distributions among dissolved, particulate, and marine-snow OM fractions to determine whether NA abundance and distribution can indicate sources for marine snow. The hypotheses were: 1. As indicated by NA yield, marine snow is fresher and therefore more biologically labile than any other OM size fraction in the water column. 2. The origin of marine snow, as an aggregate of smaller OM size fractions, can be traced through NA yield and composition. 3. NA concentration will be positively correlated with TEP concentration and TEP propensity. 4. NA yield and NA composition will indicate that smaller marine snow is derived from larger marine snow. 


\section{Materials and methods}

\subsection{Sampling site}

Samples were collected in the center of the Santa Barbara Channel off southern California, USA, in April of 1997, from the research vessel Point Sur. Nitrate concentrations were high (2.6 to $7.5 \mathrm{mM}$ ), while chlorophyll concentrations were low and varied between $20 \mathrm{mg} \mathrm{m}^{-2}$ and $45 \mathrm{mg} \mathrm{m}^{-2}$, averaging $31 \mathrm{mg} \mathrm{m}^{-2}$ (Dunne, unpublished). Wind speeds were variable (average 12 knots) with wind directions favoring upwelling (that is, wind from the west). A phytoplankton bloom was documented near our study site 6 days after our cruise by the California Cooperative Oceanic and Fisheries Investigations. The bloom caused high chlorophyll $\left(>11 \mathrm{mg} \mathrm{L}^{-1}\right)$ and nearzero nitrate concentrations at the surface. The occurrence of the phytoplankton bloom shortly after our sample collection suggests that we sampled at the beginning of an upwelling period. Upwelling is the common hydrographic condition for the Santa Barbara Channel during the spring season (Oey et al., 2001).

\subsection{Collection of marine-snow samples}

Marine-snow aggregates were hand collected using 60-ml syringes at depths of 10-20 $\mathrm{m}$ by SCUBA divers during mid morning on April 5, 7, and 8. Aggregates were selected underwater in three size fractions: small (nominal diameter $3 \mathrm{~mm}$ ), medium (nominal diameter $4 \mathrm{~mm}$ ), and large (nominal diameter $6 \mathrm{~mm}$ ) as described in Alldredge (1998). 25-50 similarly-sized aggregates were collected in each syringe. The content of syringes containing slurries of similarly-sized aggregates were pooled onboard ship and the three pooled samples, one for each size class, were subsampled for all analyses.

\subsection{Size fractionation of $O M$ in water samples}

Water samples for size fractionation by membrane filters and ultrafiltration were collected from $15 \mathrm{~m}$ depth on April 4, 5, 7, and 8 using six $30 \mathrm{~L}$ Niskin bottles. The total sample volume $(120 \mathrm{~L})$ was pressure-filtered sequentially through a $1-\mu \mathrm{m}$-pore-size Nucleopore filter and a $0.2-\mu \mathrm{m}$-pore-size Millipore filter into 20 L polyethylene containers. Single samples of filtrate for determination of DOC concentration, NA concentration, and TEP propensity were collected during this process from the $<1 \mu \mathrm{m}$ and $<0.2 \mu \mathrm{m}$ fractions. The remaining $80 \mathrm{~L}$ of filtrate was transferred to a polycarbonate tank to be used for ultrafiltration. Ultrafiltration proceeded over approximately $6 \mathrm{~h}$ as the $<0.2 \mu \mathrm{m}$ fraction was pumped across either a $3 \mathrm{kD}$ or $10 \mathrm{kD}$ (on alternate days) Amicon cross-flow ultrafiltration cartridge using a Teflon bellows pump. The $<3 \mathrm{kD}$ or $<10 \mathrm{kD}$ LMW fraction was collected in a second polycarbonate tank. Cross-flow ultrafiltration was terminated when the HMW-fraction $(<0.2 \mu \mathrm{m}$ and $>3 \mathrm{kD}$ or $10 \mathrm{kD})$ was concentrated down to approximately $2-3 \mathrm{~L}$.

Particulate organic carbon (POC) was defined as the difference in organic carbon concentration between an unfiltered sample and a sample filtered through a $0.2-\mu \mathrm{m}-$ pore-size filter. The HMW-fraction was defined as material unretained by a filter with pore size $0.2 \mu \mathrm{m}$, but retained by an ultrafiltration cartridge with molecular-weight cutoffs of $3 \mathrm{kD}$ or $10 \mathrm{kD}$. Finally, the LMW fraction was defined as material unretained by an ultrafiltration cartridge with a molecularweight cutoff of $3 \mathrm{kD}$ or $10 \mathrm{kD}$.

Note that HMW material has diameters in the size range $1 \mathrm{~nm}$ to $1 \mu \mathrm{m}$ and therefore, by definition, is colloidal (Jackson and Burd, 1998).

\subsection{Determination of organic-carbon concentrations, particle mass, and particle volume}

For marine-snow samples only, duplicate 500-750 ml samples for POC concentration determinations were filtered onto Whatman GF/F glass fiber filters, stored frozen, and analyzed on a Control Equipment Corporation CHN Analyzer, Model 440XA, according to Sharp (1991). Dissolved organic-carbon (DOC) concentrations were measured on acidified/purged samples using a Shimadzu TOC-5000 high-temperature catalytic oxidation analyzer (Benner and Hedges, 1993). Mass, volume, and organic-carbon content of marine-snow particles were determined according to Alldredge (2000) using 3 replicates of 5-10 $\mathrm{ml}$ each from each size class for each analysis.

\subsection{Determination of TEP and TEP propensity}

TEP concentration was determined in the unfiltered fractions on April 2, 3, 4, and 5 by collecting and staining TEP on 0.2- $\mu \mathrm{m}$-pore-size polycarbonate filters as described in Passow et al. (2001). Gum Xanthan was used for calibration and TEP concentrations were expressed as Gum Xanthan equivalents per liter (Xeq. $\mathrm{L}^{-1}$ ).

After collecting TEP by filtration as described, the concentration of dissolved TEP-precursors, also known as TEP propensity (Passow, 2002), was estimated using standard methods (Passow et al., 2001) in all filtered and ultra-filtered size fractions on April $2,3,4$, and 5 . TEP propensity was estimated in the $<0.2-\mu \mathrm{m}$ size fraction by determining the concentration of newly formed TEP after $24 \mathrm{~h}$, while TEP propensity was estimated after $48 \mathrm{~h}$ in the HMW and LMW fractions.

\subsection{Determination of $N A$ concentrations}

Liquid samples $(9 \mathrm{~mL})$ were pipetted into sample tubes $(15 \mathrm{~mL})$ and dried in a Savant SpeedVac. One $\mathrm{mL} 12 \mathrm{M} \mathrm{H}_{2} \mathrm{SO}_{4}$ was added, and samples were placed in an ultrasonic bath for $15 \mathrm{~min}$. After an additional $1.75 \mathrm{~h}, 9 \mathrm{~mL}$ Milli-UV+ water were added (1.2 $\mathrm{M} \mathrm{H}_{2} \mathrm{SO}_{4}$ final concentration of acid), and samples were stirred until salts dissolved. Samples were then transferred to glass ampoules and hydrolyzed at $100{ }^{\circ} \mathrm{C}$ for $3 \mathrm{~h}$. The hydrolysis was terminated by placing the ampoules in an ice bath for $5 \mathrm{~min}$.

Deoxyribose was added as an internal standard to a final concentration of $200 \mathrm{nM}$. Samples were neutralized by adding $1 \mathrm{~mL}$ sample aliquots (small volumes to reduce effervescence) to $1.44 \mathrm{~g}$ of precombusted $\mathrm{CaCO}_{3}$ in $20 \mathrm{~mL}$ glass sample tubes with 
Teflon-lined caps. After neutralization, the samples were centrifuged for $10 \mathrm{~min}$, supernatants were collected in scintillation vials, and vials were frozen until analysis. Prior to analysis, samples were run through a mixed bed of anion (AG 2-X8, 20 50 mesh, Biorad) and cation (AG 50W-X8, 100-200 mesh, Biorad) exchange resins. Samples were analyzed in triplicate.

Milli-UV+ water was used for procedural blanks. Milli-UV+ water was also used for the mobile phase and was sparged with $\mathrm{He}$ for $15 \mathrm{~min}$ before adding liquid, low-carbonate $\mathrm{NaOH}$ (Fisher). The $\mathrm{NaOH}$ mobile phase was kept under $\mathrm{He}$ atmosphere to prevent carbonate contamination. Aldoses were separated isocratically using $28 \mathrm{mM} \mathrm{NaOH}$ and a PA10 column mounted in a Dionex 500 Ion Chromatography system. Pulsed amperometric detector (Johnson and LaCourse, 1990; Rocklin and Pohl, 1983) with a gold working electrode and an $\mathrm{Ag} / \mathrm{AgCl}$ reference electrode was used. Relative standard deviations of individual sugar concentrations are typically in the range of $5-30 \%$ based on samples from the Equatorial Pacific (Skoog and Benner, 1997) and the Gulf of Mexico (Skoog et al., 1999).

Note that sum NA concentrations in the particulate fraction were estimated as the difference in sum NA concentrations between the total, unfiltered samples and samples filtered through $0.2-\mu \mathrm{m}$-pore-size filters. In addition, the estimate of compoundspecific concentrations of NA in the particulate fraction from the same difference gave large compounded errors and negative values for some concentrations. This estimate was therefore not included in the data evaluation.

\subsection{Determination of NA concentrations and enrichment factors in marine snow}

NA concentrations were determined in 7 discrete marinesnow samples. We chose to determine NA concentrations on the whole sample (that is, marine-snow aggregate-and surounding water) instead of collecting the aggregate on a filter. We did this because collecting marine snow by filtering introduces the risk of loosing aggregate fragments, since marine snow is made up of multiple smaller fragments (Alldredge, 1998; Alldredge and Gotschalk, 1990; Cowen and Holloway, 1996; Ransom et al., 1998) and can be very fragile (Alldredge and Gotschalk, 1990).

In order to estimate the NA concentration in the marinesnow aggregate only, we determined the NA concentration in the aggregate-and-surrounding-water sample, and then subtracted the surrounding-water NA concentration. In order to carry out this subtraction, we needed an estimate of the marinesnow aggregate volume, which was determined from in situ photographs. Divers randomly selected ten to twelve undisturbed aggregates in each size class to photograph individually, underwater, using a Nikonos IV underwater camera and a 1:1 close-up attachment. The aggregate volumes were then determined by computer image-analysis (Alldredge, 1998) of the photographs. We found that between 9 and $11 \%$ of the aggregate-and-surrounding-water sample volumes consisted of marine-snow aggregates, and hence deduced that seawater occupied $90 \%$ of the sample volume.
By forming a ratio between NA concentrations in marine-snow aggregates and NA concentrations in the surrounding seawater we calculated an NA enrichment factor in marine snow.

\subsection{Calculation of NA yield}

The NA yield is a practical and common way of expressing the NA-carbon as a fraction of total carbon (Hung et al., 2003; Skoog and Benner, 1997; Verdugo et al., 2004 and references therein; Witter and Luther, 2002). It is calculated by first determining the carbon in NA and then dividing by the total $\mathrm{C}$ concentration. The total NA-C concentration was calculated by multiplying the concentrations (in $\mathrm{M}$ ) of rhamnose and arabinose by 5 and all other NA concentrations by 6 . These NA-C concentrations were summed and the sum was divided by the total $\mathrm{C}$ concentration (in M). Finally this fraction was multiplied by 100 , to express the NA yield in $\%$.

\subsection{Calculation of mol fractions}

The mol fraction for a specific NA was calculated by dividing concentrations of the specific NA in M by the sum concentration of all NA in M. Finally, this fraction was multiplied by $100 \%$.

Table 1

Organic-carbon concentrations $[\mathrm{OC}]$ in various size fractions

\begin{tabular}{|c|c|c|c|c|c|}
\hline & 4 April & 5 April & 7 April & 8 April & Average \\
\hline & $\begin{array}{l}{[\mathrm{OC}]} \\
(\mu \mathrm{M} \mathrm{C})\end{array}$ & $\begin{array}{l}{[\mathrm{OC}]} \\
(\mu \mathrm{M} \mathrm{C})\end{array}$ & $\begin{array}{l}{[\mathrm{OC}]} \\
(\mu \mathrm{M} \mathrm{C})\end{array}$ & $\begin{array}{l}{[\mathrm{OC}]} \\
(\mu \mathrm{M} \mathrm{C})\end{array}$ & $\begin{array}{l}{[\mathrm{OC}]} \\
(\mu \mathrm{M} \mathrm{C})\end{array}$ \\
\hline Unfiltered & 125 & 113 & 107 & 103 & 112 \\
\hline$<0.2 \mu \mathrm{m}$ & 109 & 91 & 111 & 107 & 104 \\
\hline HMW & 10 & 11 & 13 & 15 & 12 \\
\hline LMW & 111 & 96 & 95 & 94 & 99 \\
\hline Particulate & 16 & 22 & Neg. & Neg. & 8 \\
\hline \multirow[t]{2}{*}{ Mass balance sum } & 137 & 129 & 104 & 106 & 119 \\
\hline & $\begin{array}{l}{[\mathrm{OC}] \text { as }} \\
\text { fraction } \\
\text { of TOC } \\
(\%)\end{array}$ & $\begin{array}{l}{[\mathrm{OC}] \text { as }} \\
\text { fraction } \\
\text { of TOC } \\
(\%)\end{array}$ & $\begin{array}{l}{[\mathrm{OC}] \text { as }} \\
\text { fraction } \\
\text { of TOC } \\
(\%)\end{array}$ & $\begin{array}{l}{[\mathrm{OC}] \text { as }} \\
\text { fraction } \\
\text { of TOC } \\
(\%)\end{array}$ & $\begin{array}{l}\text { Average } \\
{[\mathrm{OC}] \text { as }} \\
\text { fraction of } \\
\text { TOC }(\%)\end{array}$ \\
\hline Unfiltered & 100 & 100 & 100 & 100 & 100 \\
\hline$<0.2 \mu \mathrm{m}$ & 87 & 81 & 104 & 104 & 93 \\
\hline HMW & 8 & 10 & 12 & 15 & 11 \\
\hline LMW & 88 & 85 & 89 & 91 & 88 \\
\hline Particulate & 13 & 19 & Neg. & Neg. & 7 \\
\hline Mass balance & 110 & 114 & 97 & 103 & 106 \\
\hline
\end{tabular}

$<0.2 \mu \mathrm{m}$ denotes a sample filtered with pore size $0.2 \mu \mathrm{m}$. The HMWfraction was $<0.2 \mu \mathrm{m}$, but retained by an ultrafiltration cartridge. LMW denotes the filtrate that passed through the ultrafiltration cartridge. The particulate organic-carbon (POC) concentration is calculated as the difference in organic-carbon concentration between unfiltered samples and the sample filtered with a $0.2 \mu \mathrm{m}$-pore-size-filter $(<0.2 \mu \mathrm{m})$. Neg. denotes that the calculated value for the particulate fraction was negative. The molecular-weight cutoffs of the ultrafiltration cartridges were 10 kiloDaltons $(\mathrm{kD})$ on 4 and 7 April, and $3 \mathrm{kD}$ on 5 and 8 April. Mass balance sum denotes the sum of the concentrations in the rows "LMW," "HMW," and "Particulate." 
Table 2

Sum of all neutral aldose concentrations [Sum NA] in the various size fractions

\begin{tabular}{|c|c|c|c|c|c|}
\hline & 4 April & 5 April & 7 April & 8 April & Average \\
\hline & [Sum NA] (nM) & [Sum NA] (nM) & [Sum NA] (nM) & [Sum NA] (nM) & [Sum NA] (nM) \\
\hline Unfiltered & 437 & 655 & 446 & 363 & 475 \\
\hline$<0.2 \mu \mathrm{m}$ & 269 & 483 & 365 & 322 & 359 \\
\hline HMW & 136 & 113 & 203 & 176 & 157 \\
\hline LMW & 161 & 336 & 225 & 122 & 211 \\
\hline Particulate & 168 & 172 & 81 & 41 & 116 \\
\hline \multirow[t]{2}{*}{ Mass balance sum } & 465 & 621 & 509 & 339 & 484 \\
\hline & $\begin{array}{l}\text { Sum NA as fraction } \\
\text { of total }(\%)\end{array}$ & $\begin{array}{l}\text { Sum NA as fraction } \\
\text { of total }(\%)\end{array}$ & $\begin{array}{l}\text { Sum NA as fraction } \\
\text { f total }(\%)\end{array}$ & $\begin{array}{l}\text { Sum NA as fraction } \\
\text { of total }(\%)\end{array}$ & $\begin{array}{l}\text { Average Sum NA as } \\
\text { fraction of total (\%) }\end{array}$ \\
\hline Unfiltered & 100 & 100 & 100 & 100 & 100 \\
\hline$<0.2 \mu \mathrm{m}$ & 61 & 74 & 82 & 89 & 76 \\
\hline HMW & 31 & 17 & 45 & 48 & 36 \\
\hline LMW & 37 & 51 & 50 & 34 & 43 \\
\hline Particulate & 38 & 26 & 18 & 11 & 23 \\
\hline Mass balance & 106 & 95 & 114 & 94 & 102 \\
\hline
\end{tabular}

For definitions of size fractions and mass balance sum see legend in Table 1.

\subsection{Cluster analysis}

In order to statistically compare the similarities in composition between the different size fractions, including marine snow, we carried out a cluster analysis (Clarke and Warwick, 1994). The cluster algorithm was the group average and the clusters were based on the Bray-Curtis similarity index. The cluster analysis was performed on $\log x+1$ transformed data.

\section{Results}

\subsection{Organic carbon in various size fractions}

Only a small fraction of the organic carbon (OC) was particulate and HMW - most OC was LMW (Table 1). When forced to a total of $100 \%$ (by using the mass balance sum as $100 \%$; see
Table 1), an average of $84 \%$ of the TOC was in the LMW fraction, an average of $6 \%$ was POC, and an average of $10 \%$ was HMW.

\subsection{NA yield in various size fractions}

In contrast to the OC size distribution, the particulate and HMW size fractions contained large fractions of the NA (Table 2). The particulate and HMW-fractions accounted for an average of $56 \%$ of NA, while only $44 \%$ of NA was LMW. The average NA yields in the particulate and HMW-fractions were 8.7 and $7.7 \%$ respectively, while the average NA yield in the LMW fraction was only $1.3 \%$ (Fig. 1). The ranges for the NA yield were larger in the particulate fraction (3.1-12.6\%) than in the HMW-fraction (6.4-9.2\%). The NA yield in the LMW fraction was in the range 0.78 to $2.10 \%$ (Data not shown). That is, the NA yield increased with increasing OM size.

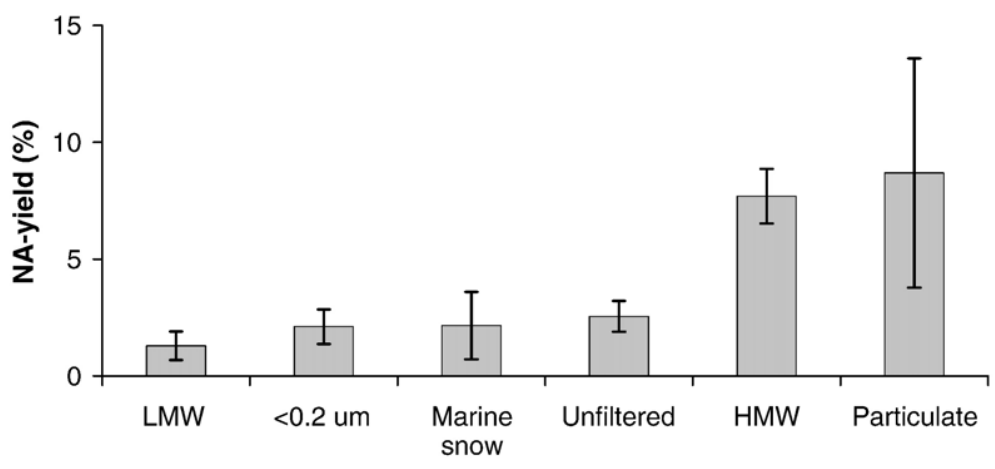

Fig. 1. Average NA yield, or the fraction of organic carbon consisting of NA-carbon in each size range. Error bars denote \pm one standard deviation. For explanations of size fractions see legend in Table 1. Note that the HMW DOM and particulate fraction are part of the unfiltered fraction and that the HMW DOM fraction is part of the $<0.2 \mu \mathrm{m}$ fraction. 
Table 3

Sum aldose concentrations in marine snow aggregates and seawater

\begin{tabular}{lllllrrr}
\hline Date & Sample & $\begin{array}{l}\text { Aggregate mean volume } \\
\left(\mathrm{mm}^{3} \mathrm{agg}^{-1}\right)\end{array}$ & $\begin{array}{l}\text { Sum aldose in seawater } \\
(\mathrm{nM})\end{array}$ & $\begin{array}{l}\text { Sum aldose in aggregate } \\
(\mathrm{nM})\end{array}$ & $\begin{array}{l}\text { Enrichment } \\
\text { factor }\end{array}$ & $\begin{array}{l}\text { Aggregate POC } \\
(\mathrm{mM})\end{array}$ & $\begin{array}{l}\text { NA yield } \\
(\%)\end{array}$ \\
\hline 5 April & 2 & 8.50 & 655 & 27,334 & 42 & 17.48 \\
5 April & 3 & 40.59 & 655 & 23,589 & 36 & 8.85 \\
5 April & 1 & 119.27 & 655 & 22,032 & 34 & 11.18 \\
7 April & 6 & 13.19 & 446 & 72,264 & 162 & 38.48 \\
7 April & 5 & 30.26 & 446 & 113,559 & 255 & 1.64 \\
7 April & 4 & 59.8 & 446 & 77,913 & 175 & 1.18 \\
8 April & 8 & 9.65 & 363 & 27,586 & 76 & 1.13 \\
8 April & 7 & 37.97 & 363 & 80,785 & 223 & 19.30 \\
\hline
\end{tabular}

The enrichment factor was calculated as the ratio between sum aldose concentration in aggregate and sum aldose concentration in seawater. NA yield was calculated from the sum of NA concentrations, divided by $\mathrm{C}$ concentration.

In contrast to the dissolved phases, the NA yield in marine snow did not increase with size (Table 3). The aldose concentrations in 7 discrete marine-snow samples was in the range 22 to $114 \mu \mathrm{M}$ and the NA yield was in the range $0.94 \%$ to $4.26 \%$, with an average of $2.16 \%$ (Table 3). NA was enriched 34 to 225 times in marine-snow aggregates (Table 3), as compared with seawater.

\subsection{NA composition}

Galactose and glucose were the most abundant NAs (Fig. 2). We found mol fractions of glucose in the range 19 to $33 \%$, while galactose had mol fractions in the range 15 to $33 \%$ (Fig. 2). The NA composition of the marine-snow fraction was distinctly different from other size fractions (Fig. 2), but when averaged among samples from different days the difference was less clear (Fig. 3). Marine snow NA composition was dominated by galactose and glucose with lower relative abundances of all other sugars (Figs. 2 and 3). Marine snow had the highest mol fraction of glucose + galactose among the size fractions. The NA composition was similar among different sizes of marine snow collected on the same day (Fig. 4). Galactose and glucose accounted for 70 to $83 \%$ of the NA (average $75 \%$ ) in marine snow, indicating that galactose/glucose-containing polymers may be major components of marine-snow.

\subsection{NAs and TEP propensity}

We found high ( $r$ of 0.73 to 0.99 ) and statistically significant $(p<0.05)$ correlations between TEP or TEP propensity and all neutral aldoses in water samples (Table 4 ). These strong correlations indicate that the polysaccharides in TEP also contain non-acidic sugars.

\subsection{Cluster analysis}

A comparison of NA composition between the marinesnow fraction and other size fractions indicated that the marinesnow NA composition was not strikingly similar to any of the other OM size fractions (Fig. 2). The unique composition of marine snow was further illustrated in the cluster analysis- all of the marine-snow samples clustered together with an $85 \%$ similarity, irrespective of collection day (Fig. 5), with the inclusion of the unfiltered sample from 5 April in the marine-snow cluster. With the exception of S7 and S8, marine-snow samples collected on the same day exhibited $>95 \%$ similarity: S1, S2 and S3 were collected on April 5; S4, S5 and S6 were collected on April 7; S7 and S8 were collected on April 8. However, marine snow was $73 \%$ similar to other size fractions, indicating some level of compositional relatedness (Fig. 5).

The unfiltered samples U2 and U3 clustered closely with samples filtered through 1.0 and $0.2-\mu \mathrm{m}$-pore-size filters, while the LMW and HMW samples clustered together.

\subsection{Integrity of the size-fractionation procedures}

Budgets of organic carbon and NA for the size-fractionation procedure indicated that the procedure did not significantly contaminate or lose material. Organic carbon and NA mass balances indicated recoveries within $15 \%$ of the initial concentrations (Table 1 and 2).

We found similar fractions of organic carbon in the HMWfractions (Table 1) as reported from other locations using the same MW cutoff ultrafilters: Kepkay et al. (1997) recovered $4 \%$ of DOC with $10 \mathrm{kD}$; Guo and Santschi (1997) recovered an average of $6.7 \%$ of DOC with $10 \mathrm{kD}$; Guo et al. (1995) recovered an average of $17.5 \%$ and $5.7 \%$ of DOC with $3 \mathrm{kD}$ and $10 \mathrm{kD}$, respectively. We had expected that the ultrafiltration cartridge with $3 \mathrm{kD}$ MW cut-off would retain a larger DOC fraction than the ultrafiltration cartridge with $10 \mathrm{kD} \mathrm{MW}$ cut-off, but the difference in DOC retention was not statistically significant.

\section{Discussion}

\subsection{Potential source material for marine snow based on NA yields}

We evaluated NA yield as an indicator of source materials for marine snow. When examining NA yields, we found that the average marine-snow yield is lower 

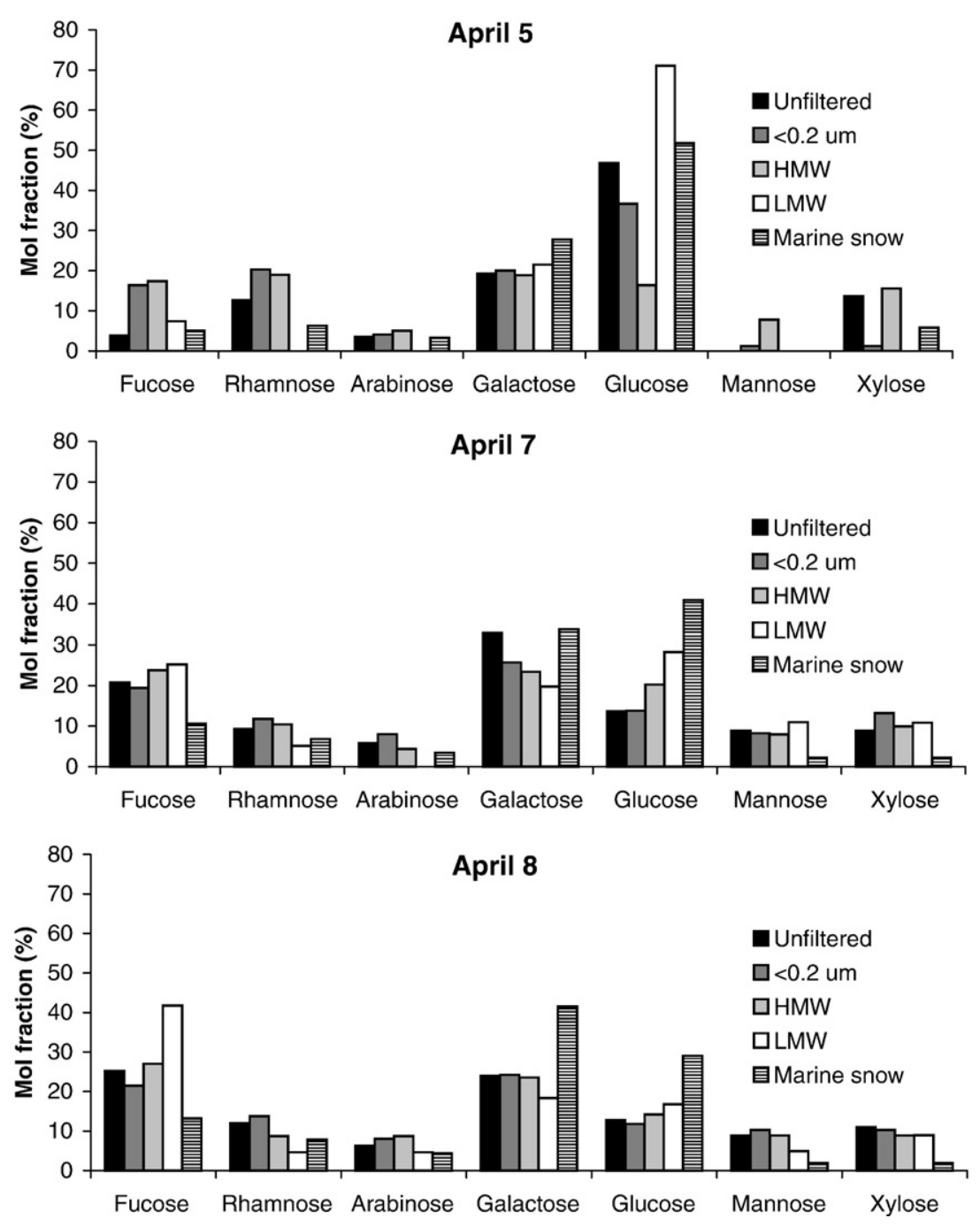

Fig. 2. Mol fractions of neutral aldoses in various size fractions. The mol fraction for marine snow is an average for snow collected that day. The numbers of marine snow samples were 3,3, and 2, for April 5, 7, and 8, respectively. The mol fraction is the fraction of total neutral aldose consisting of a specific aldose. For example, a fucose mol fraction of $18 \%$ means that $18 \%$ of the sum neutral aldose concentration consists of fucose.

than the HMW (or colloidal) and particulate fractions, and higher than the total fraction (which included particles, HMW, and LMW material), the $<0.2-\mu \mathrm{m}$ fraction (which included HMW and LMW material), and the LMW fraction (Fig. 1). It has been shown that material with low yield of biologically-labile compounds can be diagenetically derived from material with higher yields of biologically-labile material, but not the other way around (Loh et al., 2004, 2006). Hence, marine snow NA yields indicate incorporation of material from both or either of the HMW and particulate OM fractions. This aggregation is followed by bacterial degradation of the biologically-labile components, resulting in a decrease in NA yield.
There are multiple independent indications that marine snow can be rapidly degraded by bacteria in the marine environment. We found high NA-enrichment factors (ranging from 34 to 225, average 125) when comparing marine snow with surrounding seawater. These values compare well with data from Alldredge and Cox (1982), who found that marine snow had carbohydrate enrichment factors of $352 \pm 201$ when compared with seawater. These high values of biologically-labile material make marine snow a good bacterial substrate. Indeed, it has been shown that marine snow has a high number of attached bacteria (see for example Alldredge, 1990; Caron et al., 1986; Logan and Hunt, 1987). Further, C:N ratios of marine snow also indicate extensive and rapid bacterial 


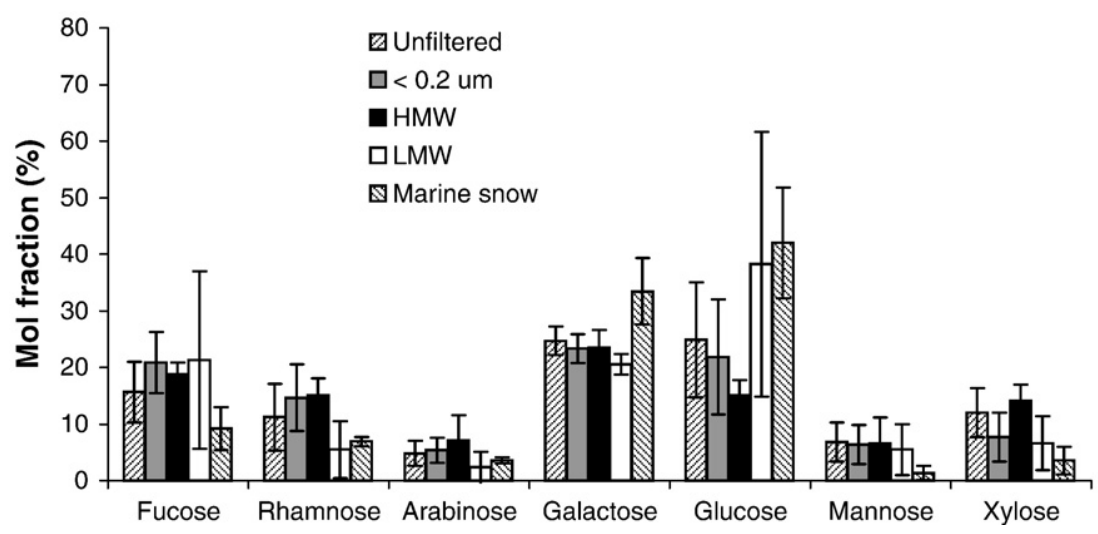

Fig. 3. Average mol fraction of neutral aldoses in various size fractions. For explanations of size fractions see legend in Table 1. Averages were calculated on samples from four days for all size fractions except marine snow, which were calculated from samples from 5, 7 and 8 April only. Error bars denote \pm one standard deviation.

degradation (Alldredge, 1979; Alldredge and Prezelin, 1983). Newly formed marine-snow aggregates have C:N ratios similar to seawater POM (Alldredge and Prezelin, 1983). In contrast, average marine snow has $\mathrm{C}: \mathrm{N}$ ratios considerably higher than those of total POM in the surrounding water (Alldredge, 1979), indicating bacterial degradation since formation.

In summary, the NA yields and a number of independent findings support the idea that marine snow is derived from particulate and HMW-fractions with subsequent bacterial degradation of biologically-labile components of the aggregate.

\subsection{Potential source material for marine snow based on NA composition}

When examining the NA composition of marine snow, it is clear that it is different from all other size fractions (Fig. 5). Marine snow collected on April 6 (S1, S2, and S3) and April 7 (S4, S5, and S6) were $>95 \%$ similar to each other, but only $73 \%$ similar to all other size fractions. The unique composition of marine snow indicates either that marine snow is formed through aggregation of selected components from other OM size fractions or that bacterial degradation has modified the composition of marine snow to a larger extent than other OM size fractions.

The average marine-snow NA composition is dominated by galactose and glucose to a larger extent than in other size fractions (Fig. 3). That is, marine snow has the highest mol fractions of galactose and glucose among all size fractions. It has been suggested that the carbohydrate components of marine snow are dominated by cellulose ( $\beta$-D-glucopyranose units in 1,4-glycosidic linkage) and $\beta-1-3$ linked glucans (Alldredge and Cox, 1982). Examples of $\beta-1-3$ linked glucans are slimes ex- creted by microorganisms. The enrichment of glucose in marine snow supports the possible presence of glucosecontaining polymers. In addition, our data also showed an enrichment of galactose in marine snow. A possible polymeric compound containing galactose is agar. Agar is present in algae and the main agar polysaccharide consists of D-galactose and 3,6-anhydrogalactose. The enrichment of both glucose and galactose in marine snow could indicate that glucans, such as cellulose and slimes, and agar-related galactans are polymeric carbohydrate components of marine snow. It is interesting to note that glucan-containing slimes and agar-related galactans both are gels.

\subsection{Estimates of NA as a fraction of total carbohydrate in marine snow}

If we use data from Alldredge and Cox (1982) for average total carbohydrate concentrations in marine snow aggregates we can estimate the NA fraction of the total carbohydrate. Alldredge and Cox (1982) give an average aggregate volume of $0.4 \mathrm{ml}$ and an average carbohydrate concentration of $59 \times 10^{-6}$ g per aggregate. If we assume that $\mathrm{CHO}$ is a representative formula for carbohydrates, we arrive at a carbohydrate-C concentration of $5.1 \mathrm{mM}$ in the marine-snow aggregate. The average POC concentrations in the marine-snow aggregates found in our study was $19.2 \mathrm{mM}$. The carbohydrate-C concentration of $5.1 \mathrm{mM}$ and the total-C concentration of $19.2 \mathrm{mM}$ give a total carbohydrate yield in marine snow of $26.5 \%$. This value can be compared with the data on average total carbohydrate yields in filtered marine samples from Pakulski and Benner (1994) of $21 \pm 7 \%$. The data from Alldredge and Cox (1982) combined with the data from our study 

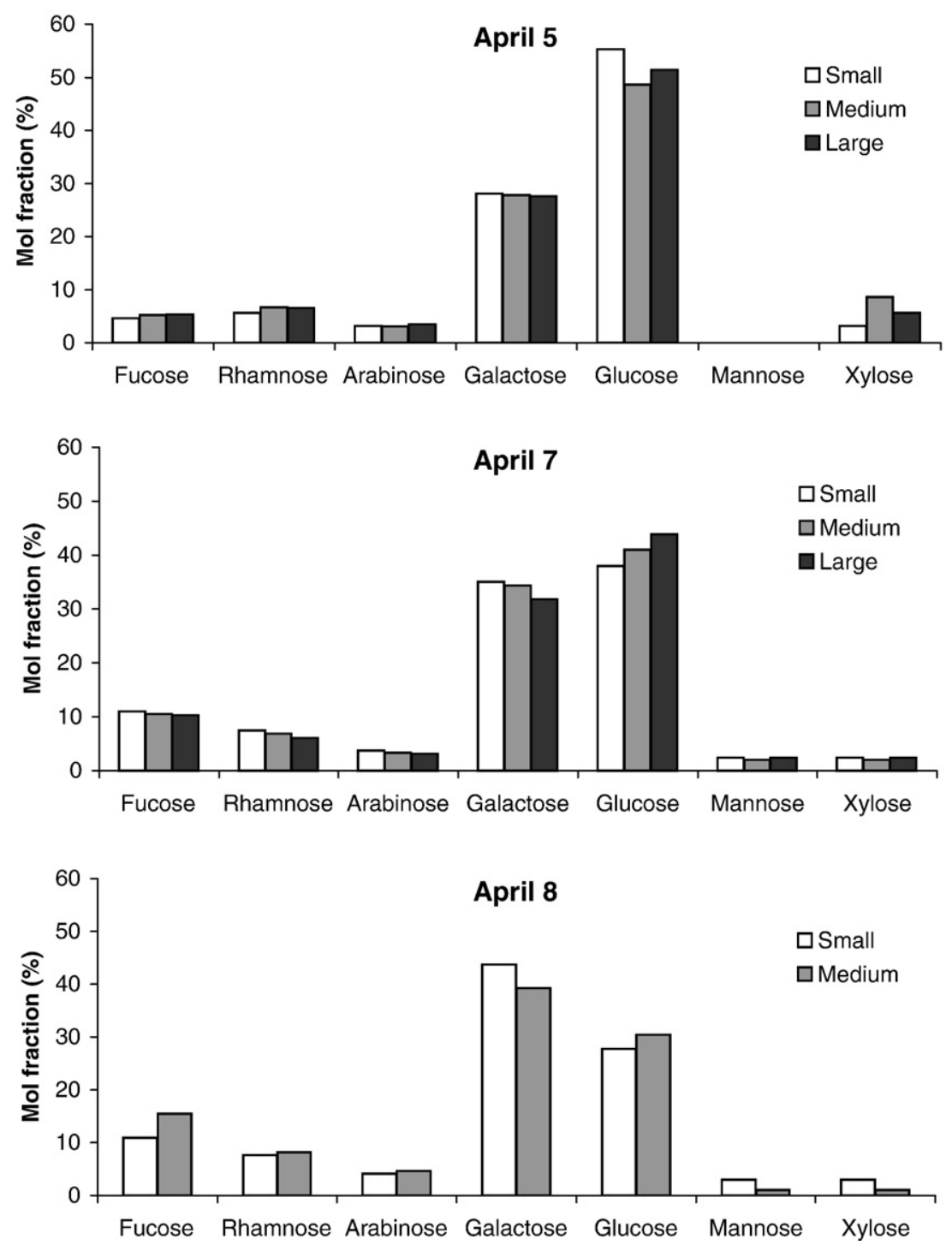

Fig. 4. Mol fractions of neutral aldoses in various size fractions of marine snow. For an explanation of mol fraction, see Fig. 2.

therefore indicate that the total carbohydrate yield is comparable with, and at the high end of, the range of carbohydrate yields found in the dissolved fraction in surface waters.

Comparing this estimated total marine-snow carbohydrate yield of $26.5 \%$ with our average marine-snow NA yield of $2.16 \%$, we estimate that we characterized less than $10 \%$ of the carbohydrates in marine snow. For comparison, Skoog and Benner (1997) found that NA comprised $7-20 \%$ of total carbohydrates in various size fractions of marine DOM. The low fraction of NA in marine-snow carbohydrates is perhaps not surprising in light of that TEP is a significant fraction of marine snow, and TEP has a high content of acidic polysaccharides.
Hung et al. (2001) suggested a role for uronic acids in particle aggregation. The determination of the amount of uronic acids in marine snow could help deduce the possible role of uronic acids in the formation of marinesnow aggregates.

\subsection{Composition of marine snow of different sizes}

It has been proposed that large marine snow aggregates may be older than smaller aggregates in some systems (Alldredge, 1998), which would manifest itself as lower NA yields in large aggregates. We compared the NA yield between different size fractions of marine snow (Table 3), and found no statistically 
Table 4

Top panel: Correlation coefficients $(r)$ between the averages of TEP concentration or TEP propensity and the averages of specific NA concentrations in the different size fractions, and the $p$-value associated with the correlation

\begin{tabular}{|c|c|c|c|c|c|c|c|c|c|c|}
\hline & & Fucose & Rhamnose & Arabinose & Galactose & Glucose & Mannose & \multicolumn{2}{|c|}{ Xylose } & Sum \\
\hline \multicolumn{11}{|c|}{ Correlation analysis carried out with water sample OM size fractions only } \\
\hline \multicolumn{2}{|c|}{$\begin{array}{l}\text { TEP concentration or } \\
\text { TEP propensity }\end{array}$} & $\begin{array}{l}0.89 \\
(p<0.05)\end{array}$ & $\begin{array}{l}0.85 \\
(p=0.07)\end{array}$ & $\begin{array}{l}0.87 \\
(p=0.06)\end{array}$ & $\begin{array}{l}0.98 \\
(p<0.05)\end{array}$ & $\begin{array}{l}0.77 \\
(p=0.13)\end{array}$ & $\begin{array}{l}0.96 \\
(p<0.05)\end{array}$ & \multicolumn{2}{|c|}{$\begin{array}{l}0.81 \\
(p=0.09)\end{array}$} & $\begin{array}{l}0.98 \\
(p<0.05)\end{array}$ \\
\hline \multicolumn{11}{|c|}{ Correlation analysis carried out with water sample OM size fractions and marine snow } \\
\hline \multicolumn{2}{|c|}{$\begin{array}{l}\text { TEP concentration or } \\
\text { TEP propensity }\end{array}$} & $\begin{array}{l}0.94 \\
(p<0.05)\end{array}$ & $\begin{array}{l}0.96 \\
(p<0.05)\end{array}$ & $\begin{array}{l}0.99 \\
(p<0.05)\end{array}$ & $\begin{array}{l}0.98 \\
(p<0.05)\end{array}$ & $\begin{array}{l}0.99 \\
(p<0.05)\end{array}$ & $\begin{array}{l}0.73 \\
(p<0.05)\end{array}$ & \multicolumn{2}{|c|}{$\begin{array}{l}0.79 \\
(p<0.05)\end{array}$} & $\begin{array}{l}0.98 \\
(p<0.05)\end{array}$ \\
\hline & $\begin{array}{l}\text { Fucose } \\
(\mathrm{nM})\end{array}$ & $\begin{array}{l}\text { Rhamnose } \\
(\mathrm{nM})\end{array}$ & $\begin{array}{l}\text { Arabinose } \\
(\mathrm{nM})\end{array}$ & $\begin{array}{l}\text { Galactose } \\
(\mathrm{nM})\end{array}$ & $\begin{array}{l}\text { Glucose } \\
(\mathrm{nM})\end{array}$ & $\begin{array}{l}\text { Mannose } \\
(\mathrm{nM})\end{array}$ & $\begin{array}{l}\text { Xylose } \\
(\mathrm{nM})\end{array}$ & $\begin{array}{l}\text { Sum } \\
(\mathrm{nM})\end{array}$ & \multicolumn{2}{|c|}{$\begin{array}{l}\text { TEP or TEP prop. } \\
\text { (ugXeq. } \mathrm{L}^{-1} \text { ) }\end{array}$} \\
\hline \multirow{2}{*}{$\begin{array}{l}\text { Unfiltered } \\
<0.2 \mu \mathrm{m}\end{array}$} & 66 & 54 & 22 & 115 & 132 & 28 & 58 & 475 & \multicolumn{2}{|c|}{182.7} \\
\hline & 74 & 54 & 19 & 82 & 85 & 21 & 25 & 359 & \multicolumn{2}{|c|}{117} \\
\hline HMW & 32 & 24 & 12 & 40 & 24 & 12 & 22 & 167 & \multicolumn{2}{|l|}{24.4} \\
\hline LMW & 38 & 9 & 3 & 44 & 95 & 10 & 12 & 211 & \multicolumn{2}{|l|}{48} \\
\hline$S$ snow & 178 & 224 & 104 & 940 & 1649 & 0 & 293 & 3388 & \multicolumn{2}{|l|}{960} \\
\hline$M$ snow & 161 & 198 & 105 & 831 & 1549 & 0 & 170 & 3014 & \multicolumn{2}{|c|}{1152} \\
\hline$L$ snow & 132 & 161 & 90 & 803 & 1580 & 0 & 92 & 2858 & \multicolumn{2}{|c|}{1037} \\
\hline
\end{tabular}

TEP concentrations were determined in unfiltered samples, while TEP propensity was determined in filtered samples. Bottom panel: Concentrations used for calculating the correlation coefficients in the top panel. TEP prop. denotes TEP propensity, $\mu \mathrm{gXeq} \times \mathrm{L}^{-1}$ denotes $\mu \mathrm{g}$ xanthan equivalents per liter. TEP concentrations were determined in unfiltered samples, while TEP propensity was determined in all other samples. NA concentrations are averages for the various size fractions sampled 4 April through 8 April. The TEP propensity is an average calculated from samples collected between 2 April and 5 April. $S$ snow, $M$ snow, and $L$ snow, denotes small, medium, and large marine snow fractions, respectively. For explanations of size fractions, see legend in Table 1.

significant differences. There was also no statistically significant correlation between marine-snow aggregate size and NA yield.

The NA composition of marine snow was similar among marine-snow size fractions sampled at the same time (Fig. 4), indicating that marine-snow aggregates of different sizes were closely related. The NA composition indicated that various size fractions of marine snow have the same source and/or that different sizes of marine snow are directly derived from each other by aggregation/ disaggregation reactions. Other studies (Alldredge, 1998; Alldredge, 1990) have also found that the majority of marine-snow aggregates sampled at the same time are of the same type regardless of size. The similarity between

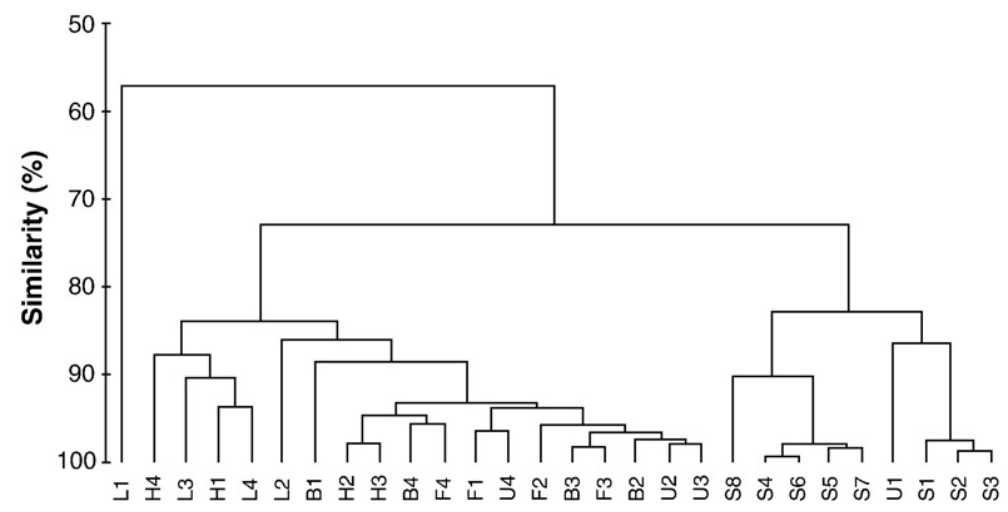

Fig. 5. Result from cluster analysis of NA composition of the various size fractions. $S$ denotes marine snow, $U$ denotes unfiltered samples, $F$ denotes samples filtered through $1 \mu \mathrm{m}$-pore size, $B$ denotes samples filtered through $0.2 \mu \mathrm{m}$-pore size, $H$ denotes HMW samples, and $L$ denotes LMW samples. 1, 2, 3 and 4 denote samples from April 4, 5, 7 and 8, respectively. A similarity diagram is interpreted by following the horizontal bar connecting samples to the intercept on the $y$-axis. The intercept is the similarity within the group of samples expressed in percent. For example, all samples denoted $S$ are connected by a horizontal line that would intercept the $y$-axis at $\sim 85 \%$ similarity, while samples S4-S7 are connected by a horizontal line that would intercept the $y$-axis at $\sim 95 \%$ similarity. 
different size fractions of marine snow indicates that aggregation/disaggregation reactions homogenize marine snow of different sizes.

\section{Summary and conclusions}

The mass balances of organic carbon and NA indicated that there were no serious contamination or loss problems. The concentrations, yields, and mol fractions of NA were similar to what has been found in other studies. Glucose and galactose had the highest relative abundance in all size fractions.

The NA yield increased with increasing molecular weight or particle size for all fractions except marine snow. This means that marine snow is not the freshest and most biologically-labile $\mathrm{OM}$ size fraction in the water column (hypothesis 1 from the Introduction). The NA yield increased in the order: $\mathrm{LMW}<$ marine snow $<$ HMW $<$ particles. Marine snow had a higher average NA yield than the LMW fraction, but lower than particle and HMW-fractions. This indicates that $\mathrm{OM}$ in marine snow could have been diagenetically derived from particulate and HMW-fractions (hypothesis 2 from the Introduction), that is, marine snow may include material from the particulate and the colloidal phase.

TEP concentration or TEP propensity was positively correlated with concentrations of all individual NAs as well as sum NA concentrations(hypothesis 3 from the Introduction), indicating that TEP contains neutral sugars in addition to the acidic polysaccharides stained in the determination of TEP concentrations.

Despite the relatively low NA yield in marine snow, marine snow was enriched in NA when compared with seawater, with enrichment factors of 34-225 (average 125). By combining data from this study with data from other studies, we estimate that $<10 \%$ of carbohydrates in marine snow comprise NAs.

There was no clear correlation between marine-snow aggregate size and NA yield, that is, there appears to be no general age difference between small and large marine-snow aggregates (hypothesis 4 from the Introduction). NA composition was similar among different marine-snow size fractions collected during the same day, indicating that aggregation/disaggregation reactions resulted in homogenizing NA composition in marine-snow aggregates of all sizes. The NA composition of marine snow was different from that of other OM size fractions, indicating either that bacterial degradation has modified the composition of marine snow to a larger extent than other $\mathrm{OM}$ size fractions or that marine snow is formed through aggregation of selected subcomponents of OM.

\section{Acknowledgements}

Annelie Skoog thankfully acknowledges a fellowship from the Swedish National Science Foundation that supported part of this work. This research was also supported by NSF OCE 94-00698 (Alldredge/Passow) and by NSF OCE 9633571 (Murray). Thanks to Carol Wyatt-Evans and Scott Bull for diving and technical assistance and to Laurie Balistrieri for assistance with sample collection. Paul Renaud provided valuable comments on the manuscript and on the statistical analysis. Annelie Skoog did part of this study in John Hedges' laboratory at the University of Washington and would like to dedicate this paper to him.

\section{References}

Alldredge, A.L., 1979. The chemical composition of macroscopic aggregates in two neritic seas. Limnology and Oceanography 24 (5), 855-866.

Alldredge, A., 1998. The carbon, nitrogen and mass content of marine snow as a function of aggregate size. Deep Sea Research Part I: Oceanographic Research 45 (4-5), 529-541.

Alldredge, A.L., 2000. Interstitial dissolved organic carbon (DOC) concentrations within sinking marine aggregates and their potential contribution to carbon flux. Limnology and Oceanography 45 (6), $1245-1253$

Alldredge, A.L., Cox, J.L., 1982. Primary productivity and chemical composition of marine snow in surface waters of the Southern California Bight. Journal of Marine Research 40 (2), $517-528$.

Alldredge, A.L., Prezelin, B.P., 1983. Primary production of marine snow during and after an upwelling event. Limnology and Oceanography 28, $1156-1167$.

Alldredge, A.L., Gotschalk, C.C., 1990. The relative contribution of marine snow of different origins to biological processes in coastal waters. Continental Shelf Research 10 (1), 41-58.

Alldredge, A.L., Passow, U., Logan, B.E., 1993. The abundance and significance of a class of large, transparent organic particles in the ocean. Deep-Sea Research I: Oceanographic Research Papers 40 (6), $1131-1140$.

Amon, R.M.W., Benner, R., 1996. Bacterial utilization of different size classes of dissolved organic matter. Limnology and Oceanography 41 (1), 41-51.

Amon, R.M.W., Fitznar, H.-P., Benner, R., 2001. Linkages among the bioreactivity, chemical composition, and diagenetic state of marine dissolved organic matter. Limnology and Oceanography 287-297 Suppl.

Benner, R., Hedges, J.I., 1993. A test of the accuracy of freshwater DOC measurements by high-temperature catalytic oxidation and UV-promoted persulfate oxidation. Marine Chemistry 41, $161-165$.

Caron, D.A., Davis, P.G., Madin, L.P., Sieburth, J.M., 1986. Enrichment of microbial populations in macroaggregates (marine snow) from surface waters of the North Atlantic. Journal of Marine Research 44, $543-565$.

Chin, W.-C., Orellana, M.V., Verdugo, P., 1998. Spontaneous assembly of marine dissolved organic matter into polymer gels. Nature 391 (6667), 568-572. 
Clarke, K.R., Warwick, R.M., 1994. Change in Marine Communities: An Approach to Statistical Analysis and Interpretation, 2nd ed. Plymouth Marine Laboratory, Plymouth, UK.

Cowen, J.P., Holloway, C.F., 1996. Structural and chemical analysis of marine aggregates: in situ macrophotography and laser confocal and electron microscopy. Marine Biology 126 (2), 163-174.

Cowie, G.L., Hedges, J.I., 1994. Biochemical indicators of diagenetic alteration in natural organic matter mixtures. Nature 369 (26), 304-307.

Edwards, M., Benjamin, M.M., Ryan, J.N., 1996. Role of organic acidity in sorption of natural organic matter (NOM) to oxide surfaces. Colloids and Surfaces A: Physicochemical and Engineering Aspects 107, 297-307.

Engel, A., 2004. Distribution of transparent exoploymer particles (TEP) in the northeast Atlantic Ocean and their potential significance for aggregation processes. Deep-Sea Research I: Oceanographic Research Papers 51, 83-92.

Guo, L., Santschi, P.H., 1997. Composition and cycling of colloids in marine environments. Reviews of Geophysics 35 (1), 17-40.

Guo, L., Santschi, P.H., Warnken, K.W., 1995. Dynamics of dissolved organic carbon (DOC) in oceanic environments. Limnology and Oceanography 40 (8), 1392-1403.

Hung, C.-C., Tang, D., Warnken, K.W., Santschi, P.H., 2001. Distributions of carbohydrates, including uronic acids, in estuarine waters of Galveston Bay. Marine Chemistry 73 (3-4), 305-318.

Hung, C.-C., Guo, L., Santschi, P.H., Alvarado-Quiroz, N., Haye, J.M., 2003. Distributions of carbohydrate species in the Gulf of Mexico. Marine Chemistry 81 (3-4), 119-135.

Hwang, J., Druffel, E.R.M., Bauer, J.E., 2006. Incorporation of aged dissolved organic carbon (DOC) by oceanic particulate organic carbon (POC): an experimental approach using natural carbon isotopes. Marine Chemistry 98 (2-4), 315-322.

Jackson, G.A., 1995. TEP and coagulation during a mesocosm experiment. Deep-Sea Research II: Topical Studies in Oceanography 42 (1), 215-222.

Jackson, G.A., Burd, A.B., 1998. Aggregation in the marine environment. Environmental Science and Technology 32 (19), 2805-2814.

Johnson, D.C., LaCourse, W.R., 1990. Liquid chromatography with pulsed electrochemical detection. Analytical Chemistry 62, 597A-598A

Kepkay, P.E., 1994. Particle aggregation and the biological reactivity of colloids. Marine Ecology Progress Series 109, 293-304.

Kepkay, P.E., Johnson, B.D., 1988. Microbial response to organic particle generation by surface coagulation in seawater. Marine Ecology Progress Series 48 (2), 193-198.

Kepkay, P.E., Jellett, J.F., Niven, S.E.H., 1997. Respiration and the carbon-to-nitrogen ratio of a phytoplankton bloom. Marine EcologyProgress Series 150 (1-3), 249-261.

Logan, B.E., Hunt, J.R., 1987. Advantages to microbes of growth in permeable aggregates in marine systems. Limnology and Oceanography 32 (5), 1034-1048.
Loh, A.N., Bauer, J.E., Druffel, E.R.M., 2004. Variable ageing and storage of dissolved organic components in the open ocean. Nature 430 (7002), 877-881.

Loh, A.N., Bauer, J.E., Canuel, E.A., 2006. Dissolved and particulate organic matter source-age characterization in the upper and lower Chesapeake Bay: a combined isotope and biochemical approach. Limnology and Oceanography 51 (3), 1421-1431.

Oey, L.Y., Wang, D.P., Hayward, T., Winant, C., Hendershott, M., 2001. "Upwelling" and "cyclonic" regimes of the near-surface circulation in the Santa Barbara Channel. Journal of Geophysical ResearchOceans 106, 9213-9222.

Pakulski, J.D., Benner, R., 1994. Abundance and distribution of carbohydrates in the ocean. Limnology and Oceanography 39 (4), 930-940.

Passow, U., 2000. Formation of transparent exopolymer particles, TEP, from dissolved precursor material. Marine Ecology-Progress Series 192, 1-11.

Passow, U., 2002. Production of transparent exopolymer particles (TEP) by phyto-and bacterioplankton. Marine Ecology-Progress Series 238, $1-12$.

Passow, U., et al., 2001. Origin of transparent exopolymer particles (TEP) and their role in the sedimentation of particulate matter. Continental Shelf Research 21, 327-346.

Ransom, B., Shea, K.F., Burkett, P.J., Bennett, R.H., Baerwald, R., 1998. Comparison of pelagic and nepheloid layer marine snow: implications for carbon cycling. Marine Geology 150 (1-4), 39-50.

Rocklin, R.D., Pohl, C.A., 1983. Determination of carbohydrates by anion exchange chromatography with pulsed amperometric detection. Journal of Liquid Chromatography 6 (9), 1577-1590.

Satterberg, J., Arnarson, T.S., Lessard, E.J., Keil, R.G., 2003. Sorption of organic matter from four phytoplankton species to montmorillonite, chlorite and kaolinite in seawater. Marine Chemistry 81 (1-2), 11-18.

Schlautman, M.A., Morgan, J.J., 1994. Adsorption of aquatic humic substances on colloidal-size aluminum oxide particles: influence of solution chemistry. Geochimica et Cosmochimica Acta 58 (20), 4293-4303.

Sharp, J.H., 1991. Review of carbon, nitrogen, and phosphorus biogeochemistry. Reviews of Geophysics 648-657 Supplement.

Skoog, A., Benner, R., 1997. Aldoses in various size fractions of marine organic matter: Implications for carbon cycling. Limnology and Oceanography 42 (8), 1803-1813.

Skoog, A., Biddanda, B., Benner, R., 1999. Bacterial utilization of dissolved glucose in the upper water column of the Gulf of Mexico. Limnology and Oceanography 44 (7), 1625-1633.

Verdugo, P., et al., 2004. The oceanic gel phase: a bridge in the DOMPOM continuum. Marine Chemistry 92 (1-4), 67-85.

Witter, A.E., Luther III., G.W., 2002. Spectrophotometric measurement of seawater carbohydrate concentrations in neritic and oceanic waters from the U.S. Middle Atlantic Bight and the Delaware estuary. Marine Chemistry 78 (2-3), 143-156. 